\title{
An Experimental and Numerical Study of Sound Propagation from a Supersonic Jet Passing through a Rigid-Walled Duct with a J-Deflector
}

\author{
Max Kandula ${ }^{\dagger}$ \\ Sierra Lobo, Inc., Jobn F. Kennedy Space Center, FL 32988, USA
}

(Received 7 September 2005; revised 1 February 2006; accepted 10 April 2006)

\begin{abstract}
The generation, propagation, and radiation of sound (the acoustical characteristics) from a perfectly expanded Mach 2.5 cold supersonic jet of $25.4 \mathrm{~mm}$ exit diameter flowing through an enclosed rigid-walled duct with an upstream J-deflector have been studied experimentally and numerically. In the experiments, the nozzle is mounted vertically, with the nozzle exit plane at a height of 73 jet diameters above ground level. Relative to the nozzle exit plane, the location of the duct inlet is varied at 10,5 , and -1 jet diameters. Far-field sound pressure levels were obtained at 54 jet diameters above ground with the aid of acoustical sensors equally spaced around a circular arc of radius equal to 80 jet diameters. Data on the acoustic field were obtained with and without the duct. The numerical simulations were carried out with the help of the OVERFLOW Navier-Stokes computational fluid dynamics (CFD) code in conjunction with a one-equation turbulence model. While the near-field sound sources were computed by the CFD code, the far-field sound was evaluated by the Kirchhoff surface integral formulation. Predictions of the far-field directivity of the overall sound pressure level (OASPL) agree satisfactorily with the experimental data. CFD calculations also suggest that there was significant entrainment of air into the duct, with the mass flow rate of entrained air being about three times the jet exit mass flow rate.
\end{abstract}

${ }^{\dagger}$ Member of the International Institute of Acoustics and Vibration (IIAV)

\section{Nomenclature}

$c$

$d_{j}$

$f$

$h$

$\dot{m}$

$M=V / c$

$p \quad-$ instantaneous pressure

$p_{m} \quad-$ mean pressure

$p^{\prime}=2 \frac{\left(p-p_{m}\right)}{\rho_{\infty} c_{\infty}^{2}}-$ dimensionless acoustic pressure disturbance

$r \quad-$ distance from the sound source

$r_{j} \quad-$ jet exit radius

$\operatorname{Re}=\rho_{j} u_{j} d_{j} / \mu_{j}-$ Reynolds number

$S t=f d_{j} / u_{j} \quad$ - Strouhal number

$T \quad-$ temperature

$u, v, w \quad-$ Cartesian velocity components

$u^{\prime}, v^{\prime}, w^{\prime} \quad-$ dimensionless velocity disturbance (scaled by $c_{\infty}$ )

$u^{*}=\sqrt{\tau_{w} / \rho} \quad-$ friction velocity

$V \quad-$ velocity

$x, y, z-$ Cartesian coordinates

$y^{*}=y u^{*} / v \quad-$ dimensionless distance from the wall

\section{Greek Symbols}

$\mu \quad$ - dynamic viscosity

$\rho \quad-$ density

$v=\mu / \rho-$ kinematic viscosity

$\tau_{w} \quad-$ wall shear stress

$\omega \quad$ - angular frequency of the disturbance

\section{Subscripts}

$j-$ jet

$m$ - time-mean

$\infty-$ ambient fluid

\section{INTRODUCTION}

In recent years there has been considerable interest in the design of exhaust ducts for jet noise mitigation systems for launch vehicles devoid of water injection. Clean (dry) launch pads with ducted exhausts are preferable to those fitted with water deluge systems for sound suppression with regard to operational costs and the frequency of launches. Thus, the overall process of sound emission from partially ducted rocket exhausts is of great practical interest in the understanding of sound suppression systems for launch vehicles. Detailed knowledge of the behaviour of the sound radiation from these ducted exhausts is useful in the design and optimisation of the sound suppression systems.

The totality of the far-field sound from ducted exhausts is composed of the transmission of sound from the free supersonic jet (upstream of the duct inlet) to the far-field, the transmission of sound within the duct, and the radiation of sound from the duct exit and the subsonic jet (exiting the duct) to the far-field. Recent experiments on enclosed ducts by Kandula et al. ${ }^{1-3}$ have indicated that the jet confinement has a significant effect on sound emission and directivity, suggesting that the duct modifies the sound generation and propagation.

According to Sir James Lighthill, ${ }^{4,5}$ noise generation from subsonic jets is mainly due to turbulent mixing, and is comprised of the contributions of large-scale and fine-scale struc-

International Journal of Acoustics and Vibration, Vol. 11, No. 3, 2006 